\title{
1. The challenge to reduce income inequality (introduction and overview)
}

\section{Peter A.G. van Bergeijk and Rolph van der Hoeven}

In September 2015 the General Assembly of the United Nations issued a statement on the 2030 Agenda for Sustainable Development (Post2015 Development Agenda) and adopted the Sustainable Development Goals (SDGs). The SDGs are in a sense the successor of the Millennium Development Goals (MDGs), but are also quite distinct. The core business of the MDG agenda was the fight against extreme poverty and fostering social progress; the SDGs are more complex and more comprehensive as they aim at sustainable development - defined in a broad sense to include its environmental, economic and social dimensions. Also the SDG process itself is much more complex. In contrast to the preparation of the MDGs, which was mostly an internal affair of top officials of the United Nations (UN) and of development fora around the Organisation for Economic Co-operation and Development (OECD) and the Bretton Woods Institutions (Fukuda-Parr, 2014; Saith, 2006) the preparations for the Post2015 Development Agenda and negotiations on the SDGs became massive, with involvement of all parts of the UN system, governments, scholars, non-governmental organizations, global philanthropists, foundations and enterprise representatives. A set of interagency activities in the UN and its specialized agencies was reflected, inter alia, in the report: Realizing the Future We Want for All (UN, 2012) that was the first main input to the consultations. The Open Working Group for the SDGs of the UN (OWG) agreed on a list of 17 goals. The process by which this list of 17 goals was drawn up included many national and global consultations which culminated in the report 'A Million Voices' (UNDG, 2013) and a report of a High Level Panel of eminent persons chaired by three heads of state (UN System Task Team on the Post-2015 Development Agenda, 2013). Indeed, Stewart (2015: 288) notes that it is a 'huge achievement to have plucked 
agreement out of a five-year maelstrom', although one can ask how many of the real poor had the opportunity to raise their voices on these issues.

Achieving agreement, however, has carried costs in terms of specificity and efficiency (Economist, 2015). The SDGs have been called a wishlist of unfocused and unattainable goals. At least four issues have been raised regarding the do-ability of the SDG project: inclusiveness in implementation, manageability, appropriate measurement and financial planning. Firstly, the idea of top-down management by (inter) governmental organization has been questioned and it has been argued that new actors for change should become part and parcel of the SDG process, including private firms, non-governmental organization and civic society (Hajer et al., 2015; Howard and Wheeler, 2015). In this sense, the SDG process itself will have to become much more inclusive in the implementation phase. Second, with 17 goals and 169 targets the process could very well become unmanageable (Stokstad, 2015) both analytically, politically and in terms of monitoring and review and of follow-up (Kindornay and Twigg, 2015). Effective policy will probably require prioritization of strategic (intrinsic and instrumental) targets (Pongiglione, 2015) and further analysis of the interdependencies in the network of targets underlying the 17 SDGs (Le Blanc 2015). A third important issue is the need to conceptually design, measure and connect the several hundreds of indicators (Hák, Janousková and Moldan, 2016) and to strengthen initiatives to increase international statistical comparability for SDG-related indicators that will be accessed both at a national and global level (Schoenmaker, Hoekstra and Smits, 2015). Fourth, an important issue is not only to set goals but also to find the financial means that are necessary to reach these goals (Sachs, 2015, Chapter 4 by Vos this volume). Financing was an issue for the MDGs, both in terms of the methodology that was deployed to arrive at the cost estimates and some of the underlying assumptions (including, for example, major efforts - in relative terms - by poor nations through domestic resource mobilization). A critical attitude towards the official and semiofficial estimates is also warranted because they seem to be driven by what is possible from the perspective of donors (the largest estimate amounts to only 0.3 per cent of world GDP) rather than by what amounts should be made available. Still it can be observed that the estimates of the global financing needs increased as the end date for the MDGs came closer (Figure 1.1), reflecting that it became increasingly clear that more finance was necessary. Moreover, even against these modest estimates, globally funding actually fell short by a third (Development Finance International and Oxfam, 2015).

The MDGs were formulated in 2000 in the benign if not optimistic global economic context of the Great Moderation but the period covered by the 


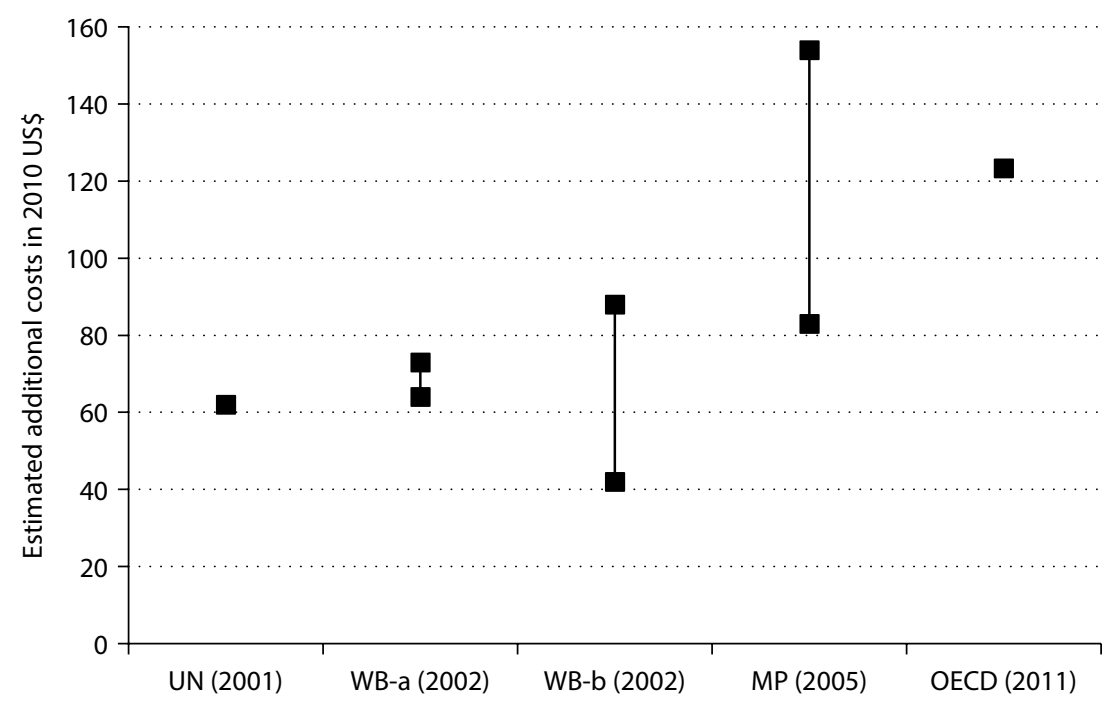

Notes:

Conversion to 2010 US\$ based on US CPI.

UN: Report of the High-Level Panel on Financing for Development.

WB-a: Financing gap for a limited group of countries in Devarajan, Miller and Swanson (2002).

WB-b: Costs related to health, education and environment in Devarajan, Miller and Swanson (2002).

MP: Millennium Project.

OECD: Atisophon et al. (2011).

Source: Based on Atisophon et al. (2011, Table 1, p. 12 and Table 2, p. 15).

Figure 1.1 (Semi) official global MDG cost estimates (billions of 2010 US\$)

MDGs ended in 2015 in the aftermath of the Great Depression, providing 'a grim future and rapid blurring of boundaries between the developed and developing contexts in terms of rising inequities and poverty' (Tiwari, 2015: 314). In this economic context, it will be even more difficult to reach productive employment, inclusive development and greater equality within and among nations. Some see no or only a very limited role for the SDGs that are 'still stuck in the straitjacket of existing structures, institutions and regimes, and therefore, the vision gets fragmented and remains at a low level of ambition' (Ghosh, 2015: 321).

This book discusses whether the SDGs have the potential to address the issues discussed above and recognize the need for transformative development. It zooms in on one of the most important questions of development 
today, how to stem the growing (income) inequality in the world (Palma, 2011; van der Hoeven, 2011; Vandemoortele, 2011; UNDP, 2013). The focus on this topic reflects the finding that the strongest hubs in the network of SDG targets occur for 'inequality, poverty and growth and employment (. . .that) all have links with 10 other goals or more' (Le Blanc, 2015: 179). Moreover, growing and persistent income inequality in many countries is an important subject that increasingly pervades in economic, social and environmental systems, and therefore warrants a study on its own. Indeed, the authors in this book provide additional reasons to focus on inequality and the potential role of SDGs in reducing inequality.

\section{BROADENING THE DEVELOPMENT AGENDA FOR THE SDG WORLD}

Richard Jolly (Chapter 2 this volume) argues that the future for development needs to be framed by five fundamental objectives: universalism, sustainability, human development, inequality and human rights, which are all embodied in the SDGs even if not always with deep commitment. He discusses three fundamental objectives in more depth: universalism, inequality and human development.

Universalism (SDGs apply to all countries) removes the long-standing weakness of development - that it was 'us' talking about the desirability of things happening in 'their' countries. This does not mean a total change of content and agenda but rather a broadening of the context and application of the SDG framework in recognition of the social and political complications which often constrain doing what 'we' (the experts) think is obviously desirable for 'them' (the developing world). Universalism may also help to strengthen the political economy analysis of the global strategy to reach sustainable development and the required policy actions. The principle of Universalism could bring more attention to comparative work regarding developed countries, with more attention to context and institutions and long run changes - and perhaps to the political economy of policy proposals.

Jolly welcomes that inequality, after thirty years of virtual neglect in international economic policy has at last been put centre stage. The opportunity of working on inequality must not be missed, because the forces of reaction will not remain side-lined for long, even though the extremes of income inequality within countries are at unprecedented levels. Already the reductions of Gini coefficients in the majority of Latin America countries are being reversed and the triumphs of conservative governments in Europe, notably in Britain and the Netherlands among others, show 
the many ways in which right-wing policies can be presented to appeal to electorates. Inequality must be analysed in a multidimensional manner and brought into mainstream policy. Wilkinson and Pickett (2009) demonstrate that inequality has a major impact on mental illness, child and adult mortality, obesity, educational performance, teenage births, homicide, imprisonment rates, levels of trust and social mobility. The common factor behind these many and widespread repercussions of inequality, is stress.

Jolly recalls that the human development paradigm has its own stimulating richness and subtleties, but that it needs to be pursued within Sen's framework of capabilities, functionings and choices. He wonders, however, why human development is so rarely part of mainstream work, either in the teaching of development or as a frame for policy analysis and policy making. This neglect of human development contains a clear message, namely that human development theory, techniques and applications need to be integrated into development teaching as well as into policy studies and consultancies. This would be an important step towards offsetting the narrow applications of neo-liberal economic teaching and policy making and the narrowness of austerity policies being promoted across Europe today. It is illogical and absurd to think that one can restore balance to a country's economy by unbalancing the lives of its people.

Jolly's five objectives relate not only to development studies but to country-by-country implementation, as already set out in the SDGs. The UN's Committee on Development Policy (CDP), has made important recommendations with respect to the SDGs, about the need for improved global governance, and for a more relevant and robust system and approach for monitoring progress towards the SDGs over the next 15 years. The CDP has also underlined the importance of ensuring that the SDGs are adapted to the national context of each country with a process of democratic consultation involving civil society as well as national parliaments.

\section{FROM MDGs TO SDGs: CRITICAL REFLECTIONS ON GLOBAL TARGETS AND THEIR MEASUREMENT}

Jan Vandemoortele (Chapter 3 this volume) provides a critical reflection on the precursors of the SDGs, the MDGs that had 2015 as target date. It is difficult to develop a counterfactual to the MDGs and it is therefore difficult to attribute developments since 2000 to success or failure of the MDGs. Positive points are that the MDGs helped to demystify 'development' for the general public and that the MDGs emphasized the striving towards as much as the achieving of global targets. However 
unintended consequences of the MDGs included the way the MDGs have been developed and formulated, especially their lack of an underlying development theory, how they have been operationalized, how they have been implemented and how this has led to a distortion in setting development priorities for structural change.

Strengths of the SDGs are getting the message to the public at large and the consultation processes by which the SDGs were developed and conceived, resulting in a broader set of areas of concern and on linking global goals towards national targets. But the SDGs are not fully inclusive, in particular because of their formulation in absolute numbers that in practical terms reduce the universality and in reflecting an old world view. For example nutrition issues are dominated by malnutrition and not by obesity.

For Vandemoortele the SDGs are not yet a universal agenda or an equitable agenda. He recommends that the implementation of the SDGs must start at the country level, whereby each and every country developing and developed alike - selects and adapts those targets that are most relevant to the national context. At the global level, three actions are required. First, the way of aggregating the global narrative needs to change. With the MDGs, this was mostly driven by global statistics and world maps with off-track countries coloured in red. With the SDGs, the global assessment needs to pay more attention to how global targets make a difference at national and sub-national levels. Second, the choice of indicators must help remedy some of the flaws in the formulation of the SDGs. The inclusion of the Palma ratio, for instance, can fix target 10.1 about inequality. This ratio measures the income share of the top 10 per cent divided by the income share of the bottom 40 per cent. The inclusion of body mass indices can fix the target on nutrition, which ignores the growing challenge of being overweight or obese. Third, one of the few truly universal targets in the SDGs cannot be left orphaned. It concerns bullet $1.2-$ By 2030, reduce at least by half the proportion of men, women and children of all ages living in poverty in all its dimensions according to national definitions. While the global narrative is already focusing on extreme poverty and hunger - which are not universal targets - the question arises who will be championing target 1.2 ? Who will compile the register of national definitions? By addressing these aspects, the considerable time and efforts invested in the SDG negotiations by countless stakeholders are likely to bear some fruit. But member states do not seem always ready to accept indicators that cover relevant, but politically sensitive, dimensions of sustainable and equitable development. 


\section{FROM BILLIONS TO TRILLIONS: TOWARDS REFORM OF DEVELOPMENT FINANCE AND THE GLOBAL RESERVE SYSTEM}

Rob Vos (Chapter 4 this volume) argues that there are many Global Public Goods (GPGs) elements in the SDG agenda. First, achieving sustainable development is a GPG in itself. Other global public goods include sustainable food security, preserving biodiversity, oceans, ecosystems, and so on, preserving a stable climate, treatment of communicable diseases and other global health issues, and stable and well-regulated international financial markets. Safeguarding these GPGs should also contribute to greater reducing international inequality. Providing these GPGs will require a stronger global partnership and much more development finance than currently available. This is acknowledged in Agenda 2030 and by SDG17, but this is little progress from the much-criticized MDG8 and its poor delivery track record. Furthermore, the AAAA - Addis Ababa Action Agenda of the third Financing for Development Conference, agreed in July 2015 just before the adaptation of the SDGs in September 2015 - seems a step backwards from the Monterrey Consensus, achieved at the first conference on Financing for Development in 2002. In Addis Ababa, no major new commitments for strengthening and widening the global partnership for development were made: no significant additional funds were pledged, no new directions for a multilateral trading system consistent with the SDGs were agreed upon or even discussed, and likewise systemic problems underlying repeated international financial instability were not even on the agenda.

The only positive outcomes were the establishment of an infrastructure fund (public-private partnership financing) and the agreement on a 'technology facilitation mechanism'. The implementation of Agenda 2030 may turn out to be shorthanded because of a weak global partnership, leaving many of the deficiencies in global governance mechanisms unresolved $^{1}$ and the risk of leaving Agenda 2030 grossly underfinanced. Ways to leverage vast new resources for sustainable development finance are revamping the global reserve system and simultaneously addressing the key weaknesses of that system to bring greater international financial stability.

According to World Bank (2015) several trillions are needed to meet the global challenges that are at the centre of the SDG agenda. While several initiatives for new sources of innovative finance, such as new international taxes, could add to existing development assistance, these would not measure up to the required trillions. The current problems of the global reserve system (asymmetric adjustments, Triffin dilemma caused by the 
dominance of the dollar, and excess reserve accumulation causing a deflationary bias to the world economy) need to be fixed. Excess reserves and new and regular issuance of Special Drawing Rights (SDRs) by the IMF could be leveraged for long-term finance for investments in sustainable development. The establishment of new multilateral development banks, such as the New Development Bank established by the BRICS countries and the Asia Infrastructure Investment Bank founded upon China's initiative are partial responses in this direction that have already been put in motion. More is needed, however, to live up to the challenge and Vos argues that opportunities are there by going at the heart of the global reserve system.

\section{GLOBAL INEQUALITY AND GLOBAL POVERTY SINCE THE COLD WAR: HOW ROBUST IS THE OPTIMISTIC NARRATIVE?}

Peter Edward and Andy Sumner (Chapter 5 this volume) discuss how the growth in global consumption since the end of the Cold War in 1990 has impacted on the co-evolution of global inequality and poverty. It is often suggested that this era of growth has led to a dramatic reduction in global poverty and to the emergence of both a new global middle class and a more equal world. They argue that this dominant and optimistic narrative on globalization since the Cold War is considerably more methodologically fragile than it at first seems. Edward and Sumner contest this mainstream view and constructed a Growth, Inequality and Poverty model (GrIP) driven by consumption, output and distribution trends, taking into account various definitions of inequality and poverty as well as various methods to make use of old and new purchasing power parity rates.

Further, Edward and Sumner suggest that this has implications for the UN goal to end global poverty by 2030 . The fall in inequality is almost exclusively attributable to the effect that the rise of China has had on between-country inequality. Changes in global inequality across the rest of the world are much more modest. Much heralded falls in global poverty have raised the consumption of the poorest, but the extent to which that is the case depends on where one draws the global poverty line as at the lower end of the global distribution a change of just 10 cents can remove 100 million people from global poverty headcounts. If one takes instead the average poverty line for all countries (a more genuinely global poverty line) of $\$ 5$ per day poverty headcounts have hardly changed since the Cold War. Meanwhile, the numbers living at risk of sliding back into poverty (between $\$ 1.90$ and $\$ 10$ a day) grew by $1.6 \mathrm{bn}$, compared to a rise of $1.1 \mathrm{bn}$ 
in the numbers living above this level, and around half of those living above this level saw their share of global consumption fall. Edward and Sumner suggest therefore that the dominant or optimistic narrative, of falling poverty and an emerging 'middle class' largely free from the threat of poverty, disguises both considerable growth in the size of the 'global precariat' living in conditions that most in the developed world would consider to be well below 'middle class' and an erosion of the financial security of a significant proportion of those living at higher consumption levels.

\section{IS LATIN AMERICA'S RECENT INEQUALITY DECLINE PERMANENT OR TEMPORARY?}

Giovanni Andrea Cornia (Chapter 6 this volume) challenges the idea that a recession by definition increases inequality. In the first decade of the twenty-first century various Latin American countries saw declines in income inequality. These declines in inequality were the result from changes in the political regimes towards the left or the centre, from deliberate policy changes as well as from changes in international conditions. Policies that helped to reduce inequality included a rise in secondary education of low-middle class children, labour market policies that included a rise in the minimum wages greater than in average wages, improved collective bargaining, especially in Southern Cone countries and a formalization of informal jobs, changes in tax policies, that included a rising tax/GDP ratio, more progressive taxation, more attention in public expenditure towards the poor, including social transfers in the form of social pensions and Conditional Cash transfers. Furthermore prudent macro policy (countercyclical fiscal/monetary policy, low deficits, low inflation, reduced external debt) contributed also to a decline in inequality.

Cornia poses the question whether the declining trend of income inequality in Latin America at the beginning of the new millennium did continue after the 2008 financial crisis and the ensuing decline in primary commodity prices. Cornia argues that from 2008 to 2012 the decline in inequality in Latin America on average continued though at a slower pace, but that 2013 showed on average a rise in inequality in Latin America, with more countries having an increase in the Gini ratio of inequality than those with a decline. Inequality went down during the sharp crisis of 2009, thanks to Keynesian policies that sustained domestic consumption and redistribution in face of falling exports. He attributes the increase in inequality in 2013, and possibly 2014 and 2015 to changes in political regimes leaning to the right, a halting of the progressive policies applied in the previous decades because of slowdown in GDP (which he labels 'political stress') 
leading to failing government approval rates. Further factors are that over 2009-2012 redistribution and the Gini fall benefitted only the poor (and no longer also the middle class, as it had happened over 2003-2009), causing an electoral shift by the middle-class in favour of centre-right regimes; ${ }^{2}$ and that serious domestic policy mistakes were made (such as repressed inflation). But he sees no abandonment of the successfully applied macro model, nor dramatic changes in the labour market policies or in the public expenditure/GDP ratio, though with reduced fiscal space because of external conditions. A preliminary regression analysis shows that in the period 2003-2008 rising exports for different categories of exporters in Latin America were related to a decline in the Gini ratio, however in the 2009-2011 and 2012-2013 periods falling exports were only in mineral exporters negatively correlated with the income inequality, that is, a drop in exports caused a rise in inequality for this group of countries.

Cornia concludes that after the structural adjustment programmes in the 1980s and fully fledged liberalization in the last decade of last century, Latin American countries were affected by strong dependency on global markets, and that as in the EU, lasting global recessions inevitably impact on growth, balance of payments, government revenue, and possibly inequality, but that after 2008, inequality continued to fall until 2012 thanks to strong initial conditions and policy commitments. However, in 2013 there were the first clear signs that inequality stopped falling (50 per cent falls and 50 per cent rises). Cornia foresees that changes in the terms of trade and in exports might affect future Gini as the 'redistributive institutions' put in place in the 2000s may be more difficult to finance. This is key especially in nine mineral exporting countries. With deteriorating growth in 2014-2015, inequality might be inevitably affected cyclically but not structurally. A structural change in Gini trend will depend on a new wave of elections. A deepening of the 2000s reforms (in the field of taxation, education and industrial policy) could help in combating the effects of the world crisis on income inequality. Despite the unparalleled inequality improvements recorded over 2002-2012, Latin America remains together with Southern Africa the region with the highest inequality in the world. The battle for a more egalitarian society needs therefore to go on.

\section{THIRTY YEARS IN AFRICA'S DEVELOPMENT: FROM STRUCTURAL ADJUSTMENT TO STRUCTURAL TRANSFORMATION?}

Tony Addison (Chapter 7 this volume) reviews 15 years of MDGs and previews the 15-year time span of the SDGs, and emphasizes the importance 
of 'structure'. The era of structural adjustment preceding (and still partially dominating) the era of the MDGs advanced a rather simple theory of structural change: the main driver was relative price incentives guiding the market to efficient outcomes. Addison recalls that the role of the state in that era was to stand back, lightly regulate (if at all), protect private property rights, and provide public goods including infrastructure. In this model, inequality might show a modest rise in the middle-stage of development but was ultimately to be contained as economies moved from low- to middle-income status, thereby providing more opportunity for all. Inclusive growth would follow almost automatically, and poverty reduction with it. But we have arrived at a point, in the era of the SDGs, at which Africa has yet to achieve the level and speed of structural transformation that is required. The last decade's super-cycle in commodities seems to be over, dangerously exposing the weakness of posting categories like the 'African lions' and their undiversified growth model. Moreover, African policy makers have yet to absorb the implications for investment in their extractive industries of what real progress on international climate change agreements will mean for the demand for Africa's exports of fossil fuels (oil and coal).

In the 1980 s achieving structural change appeared to be a straightforward process, and one to be largely driven by market mechanisms. But at the onset of the SDGs that structural change has not occurred, which illustrates the weakness of relying on market mechanisms alone (despite their importance), and points to the need for better models of state and enterprise cooperation suitable for Africa's economies. Such cooperation is inherently political, and to be effective, as well as transparent, it must mesh with the democratic politics of each country. The old forms of state and enterprise cooperation that characterized the one-party systems of post-independence Africa, and which degraded into unproductive rentseeking (and sometimes fed into violent conflict) are not viable for today's democracies. Nor are they capable of delivering integration with the global economy in ways that facilitate national structural transformation.

Today's policy agenda implied by the SDGs is subtle. Raising farm productivity; creating clusters of high value-added manufacturing and services; managing natural resource wealth in the public interest; making the right infrastructure choices; constructing financial systems that facilitate diversified economies; achieving inclusive urbanization; and adapting to climate change are challenges with no easy answers. The development states that Africa needs to create must have a deep knowledge of what the private sector is capable of achieving. Then high-value synergies of private and state action can be identified and acted upon - while ensuring that business operates within a framework of supporting regulation that 
protects the public interest. These are indeed great challenges for the international system and African people and their governments.

\section{POVERTY, EMPLOYMENT AND INEQUALITY IN THE SDGs: HETERODOX DISCOURSE, ORTHODOX POLICIES?}

Malte Luebker (Chapter 8 this volume) recalls that employment and labour issues were entirely absent from the initial set of MDGs in 2000, and that only in 2005, somewhat hastily, a new target $1 \mathrm{~B}$ was added to address this oversight with a rather simple underlying narrative: growing labour productivity, if combined with an expansion of wage employment, should help to end working poverty and thus poverty in general. The absence of references to labour institutions was regrettable: the MDGs fell short of the understanding of poverty, employment and inequality that was reached a century earlier, when Rowntree (1901) wrote his inquiry into the social conditions of the wage-earning classes of York, he could not help but wander off into the 'larger questions bearing upon the welfare of human society' and recognized that the 'legislation affecting the aggregation or the distribution of wealth' was part of the wider social problem causing poverty (Rowntree, 1901: 145). Changing the word 'land' into 'world', and updating the statistics, one of his closing sentences still rings true today: 'That in this land of abounding wealth, during a time of perhaps unexampled prosperity, probably more than one-fourth of the population are living in poverty, is a fact which may well cause great searching's of heart' (Rowntree, 1901: 304).

Luebker argues that more than a hundred years later it's about time to address the distribution of income and wealth. He therefore welcomes that the 2030 Agenda for Sustainable Development makes ample reference to employment and inequality. Goal 8 is devoted to 'Promote sustained, inclusive and sustainable economic growth, full and productive employment and decent work for all' and expands on two familiar themes, productivity and employment, while adding labour rights as a new element. While the proliferation of goals and targets prompts cynics (and a few noncynics) to dismiss the SDGs as an unattainable wish-list without focus, the more nuanced treatment of labour arguably presents a worthwhile advance in attaining a wider set of progressive policies concerned with addressing rising inequalities.

However goal 8 , if this goal is taken on its own, might not deliver on its promise of sustained, inclusive and sustainable economic growth. It is silent about labour market institutions. In their absence, productivity 
growth may not translate into higher wages for workers and hence the formula 'productivity + employment $=$ inclusive and sustainable growth' will not work its magic. Examples for this are abound, including from Asia, which are discussed in Chapter 8 . The result of such a disconnect between wages and productivity is a shift in the functional distribution of income at the expense of labour, leading to increasing inequality the very opposite of inclusive growth heralded in the preamble of the SDGs.

To achieve a more equitable growth path, Luebker argues that goal 10 of the SDGs provides some useful advice on the role of fiscal, wage and social protection policies to reduce inequalities of outcome and to achieve faster income growth for the poorest - in other words, to achieve growth with redistribution. While the SDGs are strong on some policies that have direct impact on the primary and secondary distribution of incomes, they fail to mention strengthening institutions to give workers a voice and a meaningful stake in development. Luebker argues that labour rights need to encompass the right to freedom of association. There is only an indirect reference to this in the 2030 Agenda, which invokes the Universal Declaration of Human Rights (which includes the right to form and join trade unions).

\section{CAN CATCH UP REDUCE INEQUALITY?}

Deepak Nayyar (Chapter 9 this volume) observes that, during the past 25 years, there has been a significant increase in the share of developing countries in world output, manufacturing and trade. This catch up, in aggregates, has been driven by economic growth. But the process is characterized by uneven development and emerging divergences. There is an exclusion of regions, of countries within regions, of regions within countries, and of people, leading to increasing divergences within the developing world. Asia led the process, while Latin America stayed roughly where it was, and Africa experienced regress. He identifies 14 countries (eight in Asia, four in Latin America and two in Africa, the so-called Next-14 or N14) which have led the catch up and whose experience provides insights or lessons for others. Nayyar attributes development outcomes in these countries to initial conditions, enabling institutions and supportive governments. National strategies, development policies and economic institutions in the post-colonial era that differed across countries laid the foundations. The creation of a physical infrastructure and the spread of education in society were critical elements. The role of the state in evolving policies, developing institutions and making strategic interventions, whether as a catalyst or a leader, was also central to their process of catch up. But rapid economic 
growth was not always transformed into meaningful development that improved the well-being of ordinary people. Absolute poverty declined. Yet poverty persisted. The underlying reason was that economic inequality increased almost everywhere, particularly in the N14.

Despite constraints, developing countries must ensure that the benefits of catch up are distributed in a far more equal manner between people and regions within countries. Unless growth improves the living conditions of people, it will not be possible to sustain economic growth in the long run. Thus, poverty eradication, employment creation and inclusive growth are an imperative. This is the only sustainable way forward, because it enables developing countries to mobilize their most abundant resource, people, for development, and reinforce the process of growth through cumulative causation (insofar as people provide resources on the supply side and create markets on the demand side).

Nayyar sketches reasons why other developing countries could follow the N14 and sustain high growth - large populations, demographic characteristics, and low wages - but recognizes that their potential might not be realized because of country-specific internal and external constraints. In terms of internal constraints, Nayyar emphasizes the two-way interaction between development and institutions, economic and social, as well as missing control mechanisms to deal with market failure and government failure. He would like to see a Karl Polanyi type of great transformation in the N14 and in the countries that follow in their footsteps. As to external constraints, the recent economic crisis could slow down but would not halt the catch up process. However, a faster development of alternative, non-fossil, energy sources, in the quest for sustainable development is important. The end of the first decade of the twenty-first century could be a turning point which suggests the beginning of profound changes in the balance of economic and political power in the world, in which countries either could cooperate better in a multi-polar world or where reluctance of the dominant powers to acknowledge reality could halt the process of economic and social progress. The rising tensions and the slow progress, or even regress, in global governance and economic cooperation since 2010 (stalled reform of Bretton Woods, lack of coordination of economic policies) show that global cooperation is not an automatic or assured outcome but needs to be pursued vigorously.

Nayyar formulates two interlinked hypotheses. Economic growth (catchup) is essential for reducing inequality (between and within countries), but at the same time it will be unsustainable without reducing inequality (within countries). He concludes that catch up can reduce inequality. If it does not, there will be no catch up. 


\section{CAN THE SUSTAINABLE DEVELOPMENT GOALS STEM RISING INCOME INEQUALITY IN THE WORLD?}

In the last chapter, Rolph van der Hoeven reviews processes of growing income inequality and what kind of challenges these pose for the post 2015 development agenda and the SDGs. He discusses what the drivers are for often growing income inequality, concentrating on the functional income distribution between capital and labour and the increasing share in many countries of the rich (top 1 per cent of the income curve). It is important to concentrate on the distribution of income between capital and labour as this drives personal income distribution. He relates growing functional income inequality to recent developments in the labour markets among others caused by globalization. He observes that the decline of the labour share has not halted or been reversed after the financial crisis and also does not attest to the sometimes-heard thesis that the financial crisis did hit capital owners harder than ordinary workers and their families. The share of the top 1 per cent is increasing in almost all developing countries, a consequence of the declining labour share and of greater inequality between wages themselves.

Van der Hoeven then reviews the process leading to and the outcome of the MDGs, arguing like other authors in this volume, that neglecting inequality was a great oversight of the MDGs. The SDGs in contrast do refer to reducing inequality, but van der Hoeven judges the compromise text of goal 10 on inequality and its major target too weak to be meaningful for proper implementation. He also deplores that an earlier proposal to use the Palma ratio to capture income inequality had not been retained in the final wording in goal 10 of the SDGs. He furthermore refers to the outcome of the conference on Financing for Development in July 2015 where in its final Addis Ababa Action Agenda several proposals were not retained, that could have led to greater command of national resource by developing and emerging countries, to achieve the necessary structural change and to reducing national income inequality. He argues therefore that on the basis of a first reading of the SDGs, and by judging how inequality was treated at the conference on Financing for Development one could say that the SDGs, in the way they have been currently formulated and how international agreement is reached, can as yet not be regarded as a powerful instrument to reduce inequality.

However, van der Hoeven argues that another issue that came to the fore during the preparation of the SDGs is the active involvement of civil society. Action by civil society, supported by some governments, did manage that the SDGs are now embedded in the Human Rights Declaration as well 
as in the other international instruments relating to human rights and international law, and that a follow-up and review process should be an integral part of the SDGs. Here van der Hoeven still sees opportunities to give more concrete attention to inequality in the SDGs. The Statistical Commission of the UN, in consultation with all stakeholders did set in 2016 verifiable indicators towards the targets of the SDGs, while member states are encouraged to develop national strategies, which will be part of a review process coordinated by the High Level Political Forum on Sustainable Development, based on SDG progress reports. These review processes will not only be informed by governments and international agencies, but also by civil society. They thus pose a continued and future challenge to put issues of inequality at the forefront of development policy. At various passages in the SDGs and in the Addis Ababa Action Agenda many lofty words have been said about reducing inequality.

Active involvement of civil society can thus call governments and the UN system to task on growing national and international income inequalities and demand measures which go beyond the formulation of some of the vaguely formulated goals and targets, but which do correspond to the general language of the SDGs and the Post-2015 Development Agenda. This could then form the basis of a global social contract (van der Hoeven, 2011) for an effective development partnership.

Elements of such a global social contract should include first the right to development especially the economic, social and cultural rights and the basic elements thereof in the form of non-discrimination, participation and accountability. Second, the contract should include the introduction of a global social floor, which is financially possible, but where currently political will is lacking. Third, a revitalized form of global governance, where the coherence, at national and international level between social, economic and environmental sustainable policies, is strengthened, thus allowing developing countries to strive for necessary structural transformation. This could take the form of a Global Economic Coordination Council. Deliberations at the council need not only to be based on current statistics of GDP and other economic phenomena, but also need to include alternative measures of development such as the HDI, greening economic progress and special attention in all measures to the bottom 40 per cent of the population in relation to the top 10 per cent of the population. As Ghosh (2015: 328) concludes: 'These are clearly ambitious goals, which probably require international political economy conditions that are unlikely to be met at present. But, that should not blind us to their necessity. Only a global new deal can help build the levels of trust needed to tackle shared problems and broaden the scope for effective development partnerships.' 


\section{CONCLUDING REMARKS}

All authors underline the seriousness of persistent high and/or growing inequality in many countries and see the absence of any concern for inequality in the MDGs as a great omission. The challenge that most countries are faced with is to reduce income inequality. Although the SDGs contain a goal to reduce inequality (goal 10) the target related to this goal is wholly insufficient as it relates only to progress of the bottom 40 per cent of the population. In phrasing the target in this fashion there is no sensible indicator to attest the growing importance of the growing cleavage between income of work and income of capital and the income of super rich (the top-1 per cent) which manifest themselves in much more visible form in emerging and in developed countries. Yet it is important to give attention to the behaviour of the rich, as ignoring their ascendency will put the social fabric under strain, as shown in some Latin American and other countries, as well as in many developed countries. If the burden of domestic financing of the SDGs falls on the middle class, they may well not accept such a redistributive scheme, especially in times when economic growth, because of absence of international coordination, is faltering. The contributors favour, therefore, the use of the Palma ratio to monitor progress of the inequality goal of the SDGs and to suggest national policy measures to stem growing income inequality. Several argue that the Palma ratio, despite the fact that it was not mentioned in the final formulation of the SDGs, ought to be part of national reviews on progress on SDGs, especially under pressure from civil society.

National income inequality is also circumscribed by the international context in which countries find themselves. The formulation of SDG 17 on international partnership is weak on issues of improved global governance. Also the Addis Ababa Action Agenda (the outcome of the third conference on financing for development in 2015), although mentioning the necessity of an improved international financial framework, improvement in tax collection, reduction of illicit capital outflows and avoiding tax payments by multinational enterprise in developing countries, failed to make a bold international institutional framework guiding the SDGs. Thus many developing countries are still deprived of, or need to develop more strongly, a sufficient domestic resource base to undertake redistributive measures and to finance the SDGs. 


\section{NOTES}

1. See, for example, Alonso, Cornia and Vos (2013) and Alonso and Ocampo (2015).

2. Edward and Sumner (2015) argue that the Gini ratio is misleading because top incomes have not fallen, implying that the rich get richer and that especially the upper middle incomes were taxed to pay for the poor, leading to a drop in the Gini ratio. They argue therefore for the use of the Palma ratio as an indicator and to give special attention to the behaviour of the rich and their plight to contribute to national poverty reduction.

\section{REFERENCES}

Alonso, J.A. and J.A. Ocampo (eds) (2015), Global Governance and Rules for the Post-2015 Era, London: Bloomsbury Academic.

Alonso, J.A., G.A. Cornia and R. Vos (eds) (2013), Alternative Development Strategies for the Post-2015 Era, London: Bloomsbury Academic.

Atisophon, V., J. Bueren, G. De Paepe, C. Garroway and J.-P. Stijns (2011), Revisiting MDG Cost Estimates from a Domestic Resource Mobilisation Perspective, OECD Development Centre Working Paper 306, Paris: OECD.

Devarajan, S., M.J. Miller and E.V. Swanson (2002), Goals for Development: History, Prospects, and Costs, Working Paper 2819, Washington, DC: World Bank.

Development Finance International and Oxfam (2015), Government Spending Watch Report 2015: Financing the Sustainable Development Goals: Lessons from government spending on the MDGs.

Economist (2015), Unsustainable Goals, Economist, 28 March.

Edward, P. and A. Sumner (2015), Philanthropy, Welfare Capitalism or Radically Different Global Economic Model: What Would It Take to End Global Poverty within a Generation Based on Historical Growth Patterns? Working Paper 413, Washington, DC: Center for Global Development, http://www.cgdev.org/publica tion/end-global-poverty-within-generation-historical-growth (accessed 12 June 2017).

Fukuda-Parr, S. (2014), Global Goals as a Policy Tool: Intended and Unintended Consequences, Journal of Human Development and Capabilities: A MultiDisciplinary Journal for People-Centered Development, 15(2-3), 118-131.

Ghosh, J. (2015), Beyond the Millennium Development Goals: A Southern Perspective on a Global New Deal, Journal of International Development 27, 320-329.

Hajer, M., M. Nilsson, K. Raworth, P. Bakker, F. Berkhout, Y. de Boer, J. Rockström, K. Ludwig and M. Kok (2015), Beyond Cockpit-ism: Four Insights to Enhance the Transformative Potential of the Sustainable Development Goals, Sustainability, 7, 1651-1660.

Hák, T., S. Janousková and B. Moldan (2016), Sustainable Development Goals: A Need for Relevant Indicators, Ecological Indicators, 60, 565-573.

Howard J. and J. Wheeler (2015), What Community Development and Citizen Participation Should Contribute to the New Global Framework for Sustainable Development, Community Development Journal, 50(4), 552-570.

Kindornay, S. and S. Twigg (2015), Establishing a Workable Follow-up and Review Process for the Sustainable Development Goals, Report, London: ODI. 
Le Blanc, D. (2015), Towards Integration at Last? The Sustainable Development Goals as a Network of Targets, Sustainable Development, 23, 176-187.

Palma, G. (2011), Homogeneous Middles vs. Heterogeneous Tails and the End of the Inverted-U: It is All About the Share of the Rich, Development and Change, 42(1).

Pongiglione, F. (2015), The Need for a Priority Structure for the Sustainable Development Goals, Journal of Global Ethics, 11(1), 37-42.

Rowntree, B.S. (1901), Poverty: A Study of Town Life, London and New York: Macmillan.

Sachs, J.D. (2015), Goal-based Development and the SDGs: Implications for Development Finance, Oxford Review of Economic Policy, 31, 268-278.

Saith, A. (2006), From Universal Values to Millennium Development Goals: Lost in Translation, Development and Change, 37(6), 1167-1199.

Schoenmaker, N., R. Hoekstra and J.P. Smits (2015), Comparison of Measurement Systems for Sustainable Development at the National Level, Sustainable Development, 23, 285-300.

Stewart, F. (2015), The Sustainable Development Goals: A Comment, Journal of Global Ethics, 11(3), 288-293.

Stokstad, E. (2015), Sustainable Goals from UN Under Fire, Science, 347(6223), 702-703.

Tiwari, M. (2015), Looking Back to Move Forward: the MDGs and the Road to Post-2015, Journal of International Development, 27, 313-319.

UN (2012), Realizing the Future We Want for All, New York: UN.

UNDP (2013), Humanity Divided: Confronting Inequality in Developing Countries, New York: UNDP.

United Nations Development Group (UNDG) (2013), A Million Voices, the World We Want, a Sustainable Future With Dignity For All, New York: UNDG.

UN System Task Team on the Post-2015 UN Development Agenda (2013), Statistics and Indicators for the Post-2015 Development Agenda, New York: United Nations, http://www.un.org/en/development/desa/policy/untaskteam undf/UNTT_MonitoringReport_WEB.pdf (accessed 12 June 2017).

van der Hoeven, R. (ed.) (2011), Employment, Inequality and Globalization: A Continuous Concern, London: Routledge.

Vandemoortele, J. (2011), The MDG Story: Intention Denied, Development and Change, 42(1).

Wilkinson, R. and K. Pickett (2009), The Spirit Level: Why More Equal Societies Almost Always Do Better, London: Allen Lane.

World Bank (2015), From Billions To Trillions: Transforming Development Finance Post-2015 Financing For Development: Multilateral Development Finance Development Committee 2 April 2015, Washington: World Bank. 